\title{
Novel Treatment of Hepatitis C Virus Infection for Patients with Renal Impairment
}

\author{
Goki Suda*, Koji Ogawa, Megumi Kimura, Masato Nakai, Takuya Sho, \\ Kenichi Morikawa and Naoya Sakamoto
}

Department of Gastroenterology and Hepatology, Graduate School of Medicine, Hokkaido University, Hokkaido, Japan

\begin{abstract}
Prevalence of hepatitis $\mathrm{C}$ virus (HCV) infection is high in patients with end-stage renal dysfunction, including patients undergoing hemodialysis (HD). The HCV infection itself can cause glomerulonephritis and puts individuals at increased risk of developing end-stage renal disease; fortunately, successful HCV eradication sometimes restore HCV-related renal dysfunction. Moreover, the prognosis of dialysis patients infected with HCV is significantly worse and the renal allograft survival in HCV-infected patients is also worse than in dialysis patients without HCV infection. If life prognosis is favorable, therefore, anti-HCV therapy is strongly recommended for HCV-infected patients with severe renal dysfunction. The standard therapy for HCV-infected patients with severe renal dysfunction has historically been interferon-based therapy. However, this therapy remains ineffective in achieving high, sustained viral response rates and the rate of adverse events and treatment discontinuation due to treatment-induced adverse events continues to be high in patients with severe renal dysfunction. Safe and effective anti-HCV therapies are urgently needed, and crucial, for patients with severe renal dysfunction. Recently, direct-acting antivirals (DAAs) that specifically target viral proteins have been developed, and these targets include the NS3, NS5A, and NS5B of HCV. Clinical trials have revealed high efficacy and safety of the DAA-based therapies, but patients with severe renal dysfunction were not included in the majority of these trials. However, several recent reports have shown high efficacy and safety for some regimens of DAA combination therapy for HCV-infected patients with severe renal dysfunction. In this review, we discuss novel treatments for HCV-infected patients with severe renal dysfunction and the pharmacokinetics of these drugs.

(C) 2016 The Second Affiliated Hospital of Chongqing Medical University. Published by XIA \& HE Publishing Inc. All rights reserved.
\end{abstract}

\footnotetext{
Keywords: DAAs; HCV; Hemodialysis; CKD.
}

Abbreviations: DAAs, direct-acting antivirals; $\mathrm{HD}$, hemodialysis; $\mathrm{HCV}$, hepatitis $C$ virus; IFN, interferon; PEG-IFN, pegylated-interferon; SOF, sofosbuvir; RBV, ribavirin; SMV, simeprevir; LDV, ledipasvir; eGFR, estimated glomerular filtration rate; GT, genotype; SVR, sustained viral response; SAE, serious adverse event; PTV, paritaprevir; OBV, ombitasvir; DSV, dasabuvir

Received: 29 August 2016; Revised: 21 November 2016; Accepted: 07 December 2016

DOI: $10.14218 /$ JCTH.2016.00032.

*Correspondence to: Goki Suda, Department of Gastroenterology and Hepatology, Graduate School of Medicine, Hokkaido University, North 15, West 7, Kita-ku, Sapporo, Hokkaido 060-8638, Japan. Tel: +81-11-716-1161, Fax: +81-11-7067867,E-mail: gsudgast@pop.med.hokudai.ac.jp

\section{Introduction}

Hepatitis C virus (HCV) infection affects approximately 130-150 million people worldwide and is one of the primary factors of liver cirrhosis and hepatocellular carcinoma. ${ }^{1-3}$ The rate of $\mathrm{HCV}$ infection is generally high in patients with endstage renal dysfunction, including patients on hemodialysis (HD). ${ }^{4,5}$ However, the reported prevalence of HCV infection among $\mathrm{HD}$ patients varies from $5 \%$ to approximately $60 \%$ in different countries. ${ }^{6-9}$

$\mathrm{HCV}$ infection sometimes causes extrahepatic disorders, including lymphoma, lichen planus, diabetes mellitus and renal dysfunction. ${ }^{10}$ In addition, HCV infection is the primary cause of mixed cryoglobulinemia, which is known to induce membrane-proliferative glomerulonephritis, ${ }^{11}$ and causes increased risk of developing end-stage renal disease. ${ }^{12}$ Successful HCV eradication restores the HCV-related renal dysfunction, ${ }^{13,14}$ as has been confirmed by a large cohort study. Hsu et al. ${ }^{15}$ reported that the 8-year cumulative incidence of end-stage renal disease was significantly lower in HCV-infected patients treated with anti-HCV therapy than in the untreated control group $(0.15 \%$ vs. $1.32 \%)$; in addition, the anti-HCV therapy was also found to significantly suppress acute coronary syndrome and ischemic stroke.

The prognosis of HCV-infected patients on HD is also significantly worse than that of non-HCV-infected dialysis patients. ${ }^{16-18} \mathrm{~A}$ recent meta-analysis of seven studies involving $11,589 \mathrm{HD}$ patients showed that HCV infection was an independent risk factor of mortality in HD patients. ${ }^{19}$ In addition, anti-HCV is mandatory in $\mathrm{HCV}$-infected patients who are candidates for kidney transplantation because the chance of renal allograft survival is worse in HCV-infected patients than in non-HCV-infected patients. ${ }^{20}$ Thus, HCVinfected patients with chronic renal dysfunction have an additional indication for HCV eradication therapy. The Kidney Disease Improvement Global Outcome (KIDIGO) and Japanese Society for Dialysis Therapy (JSDT) highly recommend anti-HCV therapy for dialysis patients with an HCV infection, if life prognosis is favorable. ${ }^{21,22}$ Moreover, the demographic profile of HCV-infected patients has shown a trend in increasing age, year by year, 23,24 and the number of cases with renal dysfunction are expected to increase over time due to age-related decline in the renal function. ${ }^{25}$

The standard therapy for HCV-infected patients with severe renal dysfunction has historically been interferon (IFN)-based therapy. However, this therapy remains incapable of achieving a high rate of sustained viral response (SVR), even for patients with normal renal function. ${ }^{26-28}$ Host factors, such as the 
IL-28B genotype ${ }^{29}$ or hepatitis viral protein-induced IFN signaling impairment, are considered responsible for this failure. ${ }^{30,31}$ In addition, IFN-based therapies are associated with adverse events (AEs) and of treatment discontinuation due to treatmentinduced AEs, with especially high rates in patients with severe renal dysfunction, as compared to patients with normal renal function. Therefore, safe and effective anti-HCV therapies are urgently needed and critical for patients with severe renal dysfunction, including dialysis patients.

Bartenschlager et al. ${ }^{32}$ developed an HCV replicon system in 1999, which along with the advancements in the structural analyses of HCV proteins, led to rapid progress in the development of direct-acting antivirals (DAAs). DAAs directly target viral proteins and, as such, mainly consist of three classes for combating HCV infection: those that inhibit the HCV NS3 protein, which has protease activity; those that inhibit the HCV NS5A protein; and those that inhibit the NS5B protein, which has polymerase activity.

A number of clinical trials have revealed that the IFN-free DAA combination therapies lead to significant improvements in SVR rates and safety; ${ }^{33-37}$ unfortunately, however, patients with severe renal dysfunction were excluded from the majority of these trials. Additionally, in DAA combination therapy, DAAsresistant cases, ${ }^{38,39}$ drug-drug interaction and drug excretion (Fig. 1) should be carefully monitored. Several recent studies have shown efficacy and safety for the IFN-free DAA combination therapy when used in HCV-infected patients with severe renal dysfunction ${ }^{40-42}$ (Table 1 ). According to these data, the standard therapy for HCV-infected patients with severe renal dysfunction could change from the traditional IFN-based strategy to the IFN-free DAAs strategy, similar to that used in patients with normal renal function.

In this review, we discuss the traditional and novel treatments for HCV-infected patients with severe renal dysfunction and the pharmacokinetics of these drugs.

\section{IFN-based therapy}

\section{Outline of IFN-based therapy for patients with renal dysfunction}

Before the development of DAAs, pegylated (PEG)-IFN monotherapy or in combination with ribavirin (RBV) was the standard therapy for chronic HCV infection. IFN-based therapy was also the standard therapy for patients with renal dysfunction. ${ }^{22}$ In patients with severe renal dysfunction, the clearance of IFN and RBV is reduced, because these drugs are mainly excreted renally. ${ }^{43}$ In addition, because of the high molecular weight of INF, HD is unable to remove significant amounts of it. Moreover, patients with renal dysfunction often have anemia or other complications, and INF- or RBV-induced AEs become more problematic.

\section{Efficacy and safety of IFN monotherapy for patients with renal dysfunction}

\section{IFN monotherapy}

In 2008, Gordon et al. ${ }^{27}$ reported a meta-analysis of clinical trials using INF monotherapy for hepatitis $C$ treatment in patients on chronic HD. A total of 20 clinical studies between 1966 and 2007 were analyzed. The SVR rates ranged from $19 \%$ to $71 \%$ and the overall SVR rate was $41 \%$ [ $95 \%$ confidence interval (CI): 33-49]. In addition, the overall treatment discontinuation rate was relatively high, at $26 \%(95 \% \mathrm{CI}$ : 20-34).

\section{PEG-INF monotherapy}

In 2015, Fabrizi et al. ${ }^{44}$ reported a meta-analysis of clinical trials using PEG-INF monotherapy for hepatitis $\mathrm{C}$ treatment in

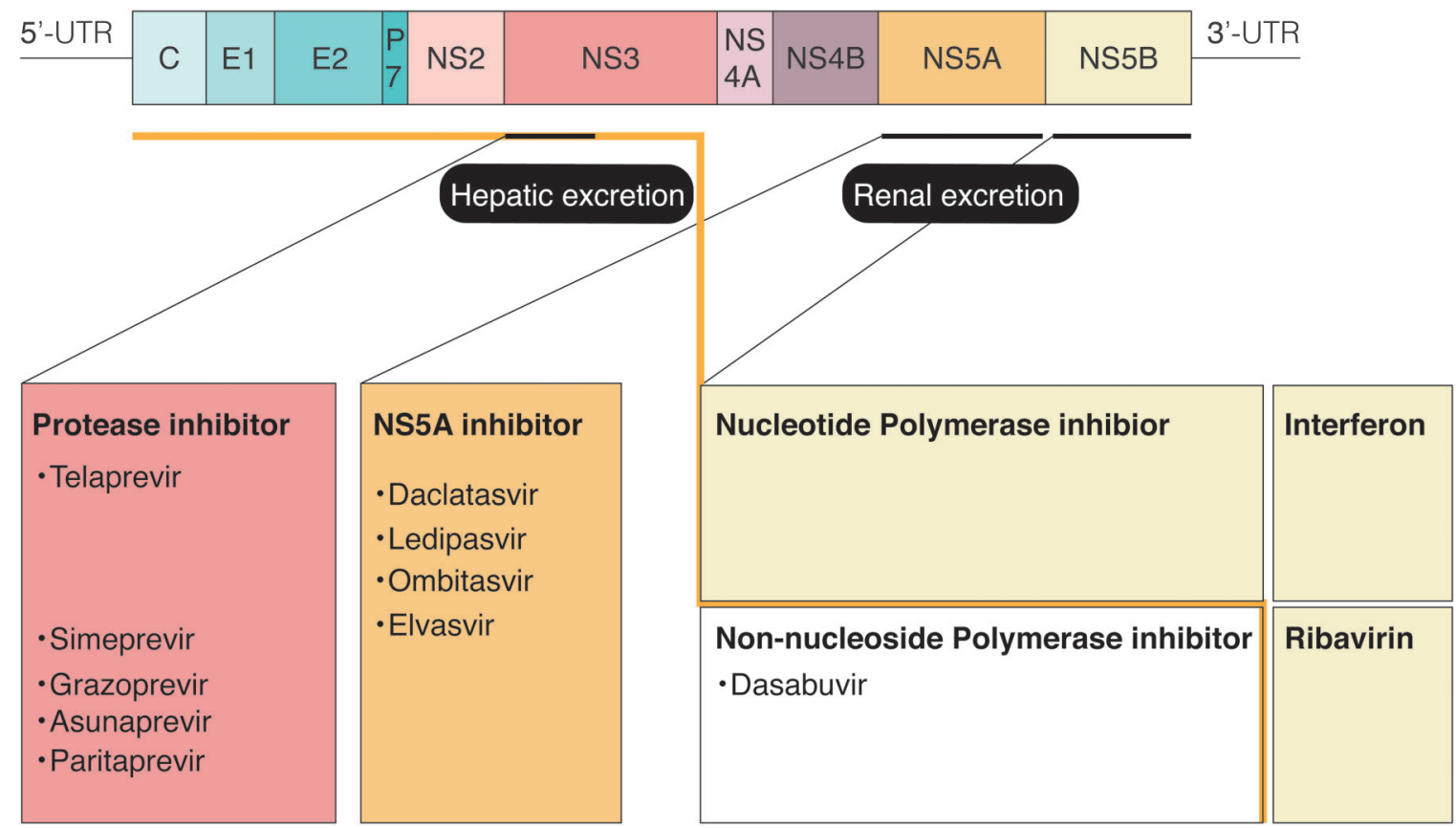

Fig. 1. Anti-HCV drugs and excretion. 
Suda G. et al: Novel therapy for HCV in renal impairment

Table 1. Overview of the efficacy and safety of IFN-free DAAs combination therapies

\begin{tabular}{|c|c|c|c|c|c|c|c|}
\hline $\begin{array}{l}\text { Treatment regimen } \\
\text { (treatment duration) }\end{array}$ & Patients & HCV GT & Number & $\begin{array}{l}\text { SVR rate }(\%) \\
(\mathrm{ITT})\end{array}$ & SAE (\%) & $\begin{array}{l}\text { Treatment } \\
\text { discontinued } \\
\text { rate }(\%)\end{array}$ & Special notes \\
\hline \multicolumn{8}{|c|}{ Grazoprevir/elbasvir (12 weeks) } \\
\hline$(\text { Roth et al. })^{40}$ & $\begin{array}{l}\text { CKD 4/5 } \\
\text { including } \\
\mathrm{HD}\end{array}$ & GT1 & 122 & $\begin{array}{l}94.2 \\
(115 / 122)\end{array}$ & $\begin{array}{l}14.4 \\
(16 / 111)\end{array}$ & 0 & $\begin{array}{l}\text { Adverse } \\
\text { effects were } \\
\text { comparable to } \\
\text { placebo } \\
\text { control group }\end{array}$ \\
\hline \multicolumn{8}{|c|}{ Paritaprevir/ritonavir/ombitasvir, and dasabuvir with or without RBV (12 weeks) } \\
\hline$(\text { Pockros et al. })^{41}$ & $\begin{array}{l}\text { CKD 4/5 } \\
\text { including } \\
\text { HD }\end{array}$ & GT1 & 20 & $90(18 / 20)$ & $20(4 / 20)$ & 0 & $\begin{array}{l}\text { RBV add-on in } \\
\text { patients with } \\
\text { GT1a HCV } \\
\text { infection }\end{array}$ \\
\hline \multicolumn{8}{|c|}{ Daclatasvir/asunaprevir (24 weeks) } \\
\hline$(\text { Suda et al. })^{42}$ & HD & GT1 & 21 & $95.5(20 / 21)$ & $5(1 / 21)$ & $5(1 / 21)$ & \\
\hline$(\text { Toyoda et al.) })^{72}$ & HD & GT1b & 28 & $100(28 / 28)$ & 0 & $3.6(1 / 28)$ & \\
\hline$(\text { Kawakami et al.) })^{68}$ & $\mathrm{HD}$ & GT1 & 18 & $100(18 / 18)$ & $5.5(1 / 18)$ & 0 & \\
\hline \multicolumn{8}{|c|}{ Sofosbuvir-based therapy } \\
\hline \multirow[t]{2}{*}{$\begin{array}{l}\text { SOF/PEG-IFN/RBV, } \\
\text { SOF/RBV, } \\
\text { SOF/SMV, } \\
\text { SOF/SMV/RBV } \\
\quad(\text { Saxena et al. })^{79}\end{array}$} & eGFR $<45$ & GT1-6 & 73 & $83(53 / 64)$ & $22(16 / 73)$ & $7(5 / 73)$ & $\begin{array}{l}\text { Patients with } \\
\text { reduced renal } \\
\text { function } \\
\text { experienced } \\
\text { more } \\
\text { frequently, } \\
\text { worsening of } \\
\text { the renal } \\
\text { function and } \\
\text { serious } \\
\text { adverse } \\
\text { effects }\end{array}$ \\
\hline & eGFR $<30$ & GT1-3 & 17 & $88(15 / 17)$ & $18(3 / 17)$ & $6(1 / 17)$ & \\
\hline $\begin{array}{l}\text { SOF/SMV (12 weeks) } \\
(\text { Nazario et al. })^{80}\end{array}$ & $\begin{array}{l}\text { eGFR }<30 \\
\text { including } \\
\mathrm{HD}\end{array}$ & GT1 & 17 & $100(17 / 17)$ & 0 & 0 & \\
\hline \multicolumn{8}{|l|}{ SOF/SMV (12 weeks) } \\
\hline \multicolumn{8}{|l|}{ SOF/LDV (12 weeks) } \\
\hline$(\text { Singh et } a l .)^{83}$ & HD & $\mathrm{GT} 1,3,4$ & 8 & $87.5(7 / 8)$ & 0 & 0 & \\
\hline $\begin{array}{l}\text { SOF/PEG-IFN/RBV, } \\
\text { SOF/RBV, } \\
\text { SOF/SMV, } \\
\text { SOF/SMV/RBV } \\
\quad(\text { Beinhardt et al.) })^{84}\end{array}$ & $\mathrm{HD}$ & $\mathrm{GT} 1,3,4$ & 10 & $90(9 / 10)$ & $50(5 / 10)$ & 0 & \\
\hline $\begin{array}{l}\text { SOF/LDV } \\
\text { SOF/SMV } \\
\text { SOF/DCV } \\
\text { SOF/RBV } \\
(12-24 \text { weeks) } \\
(\text { Desnoyer et al.) }\end{array}$ & HD & GT1,2 & 12 & $83 \%(10 / 12)$ & 0 & 0 & \\
\hline
\end{tabular}

Abbreviations: DAAs, direct-acting antivirals; HD, hemodialysis; HCV, hepatitis C virus; IFN, interferon; PEG-IFN, pegylated-interferon; SOF, sofosbuvir; RBV, ribavirin; SMV simeprevir; LDV, ledipasvir; eGFR, estimated glomerular filtration rate; GT, genotype; SVR, sustained viral response; SAE, serious adverse event.

patients on chronic HD. They analyzed 744 patients from 24 clinical studies, including 5 randomized control studies performed between 2006 and 2014. Overall, the estimated
SVR was $40 \%$ (95\% CI: $35-46)$. The dropout rate was $14 \%$ (95\% CI: 9-20). The most frequent AEs requiring discontinuation of treatment were hematological and gastrointestinal 
problems. The authors concluded that the efficacy and safety of PEG-INF monotherapy for dialysis patients with severe renal dysfunction was unsatisfactory.

\section{Efficacy and safety of IFN and RBV for patients with renal dysfunction}

In 2014, Fabrizi et al. ${ }^{45}$ reported a meta-analysis of clinical trials using PEG-INF and RBV for hepatitis $\mathrm{C}$ treatment in patients on chronic HD. They analyzed 287 patients from 11 clinical studies, including 2 control studies, performed between 1998 and 2013. Overall, the estimated SVR was $60 \%$ (95\% CI: 47-71). The dropout rate was $18 \%$ (95\% CI: $8-35)$. The most frequent AEs requiring discontinuation of treatment were anemia $(11 / 46,23 \%)$ and infections (6/46, 13\%).

However, in some countries, RBV administration is contraindicated in patients with severe renal dysfunction, because RBV is eliminated through the kidney and cannot be eliminated by dialysis. ${ }^{21,43}$

\section{IFN-based therapy with HCV NS3 protease inhibitors for patients with renal dysfunction}

The first-generation protease inhibitors, including telaprevir, boceprevir and the PEG-IFN and RBV combination therapy, could achieve an SVR rate of $75 \%$ to $85 \%$ in patients with normal renal function. ${ }^{46-48}$ However, severe AEs, including cutaneous rash, ${ }^{49}$ anemia and renal impairment, ${ }^{50}$ were reported. The data regarding the triple antiviral therapy for HCV-infected patients with renal dysfunction are limited, ${ }^{51-55}$ but the reported SVR rates have varied between $17 \%$ and $86 \%$ and the dropout rates have varied between $10 \%$ and $20 \%$.

\section{IFN-free DAA combination therapy}

In the case of DAA administration to patients on $H D$, special attention should be paid to drug-drug interaction, because these patients usually receive various drugs. Caution is necessary, especially for ritonavir administration, which inhibits CYP3A4.

\section{Grazoprevir and elbasvir combination therapy for HCV- infected patients with renal dysfunction}

Grazoprevir is an HCV NS3 protease inhibitor with broad in vitro activity against multiple HCV genotypes and resistance variants. ${ }^{56}$ Grazoprevir is administered at a dose of $100 \mathrm{mg}$ once a day and is a substrate of CYP3A4, P-gp and OATP. This drug is eliminated mostly through liver, with less than $1 \%$ excreted renally. ${ }^{57}$ Elbasvir is an HCV NS5A inhibitor with potent multiple genotypic antiviral activity in vitro. ${ }^{58}$ Elbasvir is administered at a dose of $50 \mathrm{mg}$ once a day and it is also a substrate of CYP3A4, P-gp and OATP. ${ }^{57}$ Similar to grazoprevir, elbasvir is mainly metabolized through the liver, with less than $1 \%$ eliminated renally. ${ }^{57}$

The pharmacokinetics of elbasvir were studied in non$\mathrm{HCV}$-infected dialysis subjects and subjects with severe renal dysfunction, and then compared with healthy controls. ${ }^{57}$ The area under the curve (AUC) was $25 \%$ higher for the HD subjects and $46 \%$ higher for the subjects with severe renal dysfunction, compared with the controls. In the pharmacokinetic analysis of grazoprevir in HCV-infected patients, the AUC was $10 \%$ higher for the HD patients and $40 \%$ higher for the patients with severe renal impairment, compared to the controls. In addition, elbasvir and grazoprevir are not removed by HD.

Several trials showed high efficacy and safety of elbasvir and grazoprevir for HCV-infected patients with various complications. ${ }^{40,59-62}$ In a phase 3 trial for patients with genotype 1 or 4 HCV and HIV co-infection (C-EDGE CO-INFECTION), when this combination therapy was administered for 12 weeks an SVR rate of $96 \%$ was achieved $(210 / 218) .{ }^{63}$

The C-SURFER is a phase 3 randomized study designed to evaluate the safety and efficacy of grazoprevir and elbasvir combination therapy for genotype $1 \mathrm{HCV}$-infected patients with severe renal dysfunction (stage 4-5 chronic kidney disease (CKD), including HD patients). ${ }^{40}$ Two-hundred-and-twenty-four patients with severe renal dysfunction were randomly assigned to receive grazoprevir and elbasvir for 12 weeks $(n=111)$ or placebo (deferred treatment group, $n=113$ ). In addition, 11 patients were not randomized and received the dual therapy, and they underwent intensive pharmacokinetic evaluation. Of these 235 patients, 179 (76\%) needed HD, $122(52 \%)$ had HCV genotype 1 a infection, 14 (6\%) were cirrhotic, 80 (34\%) had diabetes mellitus and 108 (46\%) were African American. In patients treated with grazoprevir and elbasvir, the $S R_{12}$ rate (ITT analysis) was $94.3 \%$ (115/122). And, in the modified full analysis set (excluding patients who failed to receive one or more doses of drug due to issues unrelated to the hepatitis $C$ treatment), the $\mathrm{SVR}_{12}$ rate was $99 \%(115 / 116)$. In the safety analysis, no patients in the grazoprevir and elbasvir therapy group were found to have discontinued because of an $A E$. On the contrary, in the control group, 5 (4\%) patients discontinued the placebo treatment due to AEs. In the grazoprevir and elbasvir therapy group, AEs were reported for $76 \%$ of the cases; however, these results were comparable with the placebo group (84\%). Thus, the C-SURFER study indicated that grazoprevir and elbasvir for 12 weeks was safe and effective, even in patients infected with HCV genotype 1 and stage 4-5 CKD.

\section{Paritaprevir (PTV)/ritonavir, ombitasvir (OBV), and dasabuvir (DSV) with or without RBV combination therapy for HCV-infected patients with renal dysfunction}

OBV is an HCV NS5A inhibitor, PTV is a second-generation NS3 protease inhibitor, ritonavir is the pharmacokinetic enhancer that is a CYP3A inhibitor, and DSV is a non-nucleoside NS5B polymerase inhibitor. PTV, ritonavir and OBV are administered at a dose of $150 \mathrm{mg}, 100 \mathrm{mg}$ and $25 \mathrm{mg}$ once a day, respectively. DSV, however, is administered at a dose of $250 \mathrm{mg}$ twice a day. PTV is a substrate of CYP3A4/5, P-gp, OATP1B1 and OATP1B3 and is metabolized mainly through the liver. ${ }^{64}$ The single-dose pharmacokinetics of PTV were studied in nonHCV-infected subjects with severe renal dysfunction, and compared with subjects with normal renal function. The AUC values increased by $45 \%$ in subjects with severe renal dysfunction, compared with the controls. ${ }^{64}$ Ritonavir is administered to inhibit CYP3A4, resulting in enhancement of the PTV effect. The single-dose pharmacokinetics of ritonavir were studied and the AUC values increased by $114 \%$ in subjects with severe renal dysfunction, compared with the control subjects. OBV is metabolized mainly by amide hydrolysis and oxidative metabolism, and biliary excretion is the major elimination route. The result of single-dose pharmacokinetic study of OBV indicated that the AUC values were similar between subjects with severe renal dysfunction and controls. DSV is a substrate of CYP3A4, $\mathrm{P}$-gp, BCRP and organic cation transporter 1 , and is mainly 
metabolized through the liver. The single-dose pharmacokinetics of DSV were studied and the AUC values increased by $50 \%$ in subjects with severe renal dysfunction, compared with the control subjects. ${ }^{64}$

In clinical trials, this regimen showed a high rate of $\mathrm{SVR}_{12} \cdot{ }^{36,65,66}$ However, patients with severe renal dysfunction were not included. Recently, the RUBY-I study investigated the safety and efficacy of these combination therapy in patients with stage 4 or 5 CKD. ${ }^{41}$ This prospective multicenter study included 20 treatment-naive patients with HCV genotype 1 infection and without cirrhosis. Six patients with CKD stage 4 and 14 patients with CKD stage 5 or who were on HD were included. Fourteen patients $(70 \%)$ had the IL-28B non-CC genotype and 4 patients (20\%) had F3 liver fibrosis. Thirty-three patients with HCV genotype 1 a were treated with this combination therapy and RBV and 7 patients with HCV genotype $1 \mathrm{~b}$ infection were treated with the combination therapy alone. Overall, $90 \%(18 / 20)$ of the patients achieved $\mathrm{SVR}_{12}$ (95\% CI: 69.9-97.2). One patient died after finishing the treatment, due to issues unrelated to the treatment, and 1 patient experienced virological relapse. In the safety analysis, all 20 patients were found to have completed the 12 weeks of treatment. Ninety-five percent of the enrolled patients experienced AEs; however, they were mostly mild or moderate and no patient discontinued treatment due to AEs. A common AE was anemia in the RBV add-on group, and RBV therapy was interrupted in 9 patients due to anemia.

\section{Asunaprevir (ASV) and daclatasvir (DCV) combination therapy for HCV infected patients with renal dysfunction}

DCV is a first-in-class NS5A inhibitor and has potent pangenotypic antiviral activity in vitro. ${ }^{67} \mathrm{ASV}$ is a second-generation NS3 protease inhibitor and has antiviral activity against multiple HCV genotypes in vitro. ASV is administered at a dose of $100 \mathrm{mg}$ twice a day, and is metabolized by CYP3A and eliminated mostly in the feces. ${ }^{37}$ The pharmacokinetics of ASV were studied in non-HCV-infected dialysis subjects and compared with healthy controls. ${ }^{37}$ The $\mathrm{C}_{\max }$ was $28.6 \%$ higher and the AUC was $10.1 \%$ lower in dialysis subjects, compared with the controls. Recently, Kawakami et al. ${ }^{68}$ reported the ASV pharmacokinetics determined in HCV-infected dialysis patients and compared with HCV-infected patients with normal renal function. The AUC from 0 to $6 \mathrm{~h}$ (AUC 0-6 h) of ASV was significantly lower in HD patients than in the controls $(1345 \pm 741 \mathrm{lgh} / \mathrm{mL}$ vs. $4769 \pm 1964 \mathrm{lgh} / \mathrm{mL})$. DCV is administered at a dose of $60 \mathrm{mg}$ once a day, and is metabolized by CYP3A and eliminated mostly in the feces (88\%). ${ }^{69}$ The pharmacokinetics of DCV were also studied in non-HCV-infected dialysis subjects and compared with healthy controls. ${ }^{69}$ The AUC was $26.9 \%$ higher in dialysis subjects, compared with the controls.

In phase 3 trials for patients with genotype $1 \mathrm{~b}$ infection, the DCV/ASV combination therapy for 24 weeks achieved a high SVR rate $(82-95 \%))^{39,70,71}$ However, data of efficacy and safety for HCV-infected patients with renal dysfunction were not obtained in these clinical trials. This regimen has been approved in several countries and the real-world outcomes have already been reported, including the efficacy and safety of this combination therapy for HD patients. ${ }^{42,68,72}$ We reported the efficacy and safety of DCV/ASV combination therapy from a study of $21 \mathrm{HCV}$-infected dialysis patients. ${ }^{42}$ A total of $95.5 \%(20 / 21)$ of the patients achieved $\mathrm{SVR}_{12}$. Of the 21 patients on dialysis, 3 had NS5A RAVs-Y93H and all of the patients with NS5A RAVs achieved $S_{V R} R_{12}$. On the other hand, 1 patient with NS3 D168E RAVs at baseline experienced relapse at 4 weeks post-treatment. In the safety analysis, $95.5 \%$ of the enrolled patients completed the 24 weeks of therapy and no patient had lethal AEs. One patient discontinued treatment due to an elevated alanine aminotransferase (ALT) level. ALT elevations were observed in $14.3 \%$ of the patients, and this result is comparable with a phase 3 study conducted in Japan. ${ }^{39}$

Toyoda et al..$^{72}$ used propensity score matching to compare the efficacy and safety of the DCV/ASV combination therapy in 28 patients on HD with those of 56 patients without renal dysfunction. They showed that the rate of $S R_{12}$ was $100 \%$ $(28 / 28)$ for the dialysis patients $(94.6 \%$ for the patients with normal renal function) and that serum HCV RNA disappeared significantly earlier in the HD patients. In addition, they showed that treatment-related AEs were comparable between the two groups. Additionally, Kawakami et al. ${ }^{68}$ analyzed the pharmacokinetics of DCV and ASV in the dialysis setting and showed a high efficacy of this combination therapy for dialysis patients, with an SVR rate of $100 \%(18 / 18)$.

\section{Sofosbuvir-based therapy for HCV-infected patients with renal dysfunction}

Sofosbuvir is a potent nucleoside NS5B polymerase inhibitor that has high genetic barrier and high efficacy. Sofosbuvir is usually administered at a dose of $400 \mathrm{mg}$ once a day combined with other DAAs, such as the NS5A inhibitors ledipasvir or DCV, and the NS3 protease inhibitor simeprevir or RBV. Sofosbuvir is firstly metabolized to a pharmacologically active nucleoside analog triphosphate GS-461203.73 Subsequently, GS-461203 is metabolized to the inactive metabolite GS-331007. Importantly, this GS-331007 is mainly excreted through the kidney. The single-dose pharmacokinetics of sofosbuvir were studied in non-HCV subjects with moderate (estimated glomerular filtration rate (eGFR) between $30-50 \mathrm{~mL} / \mathrm{min} / 1.73 \mathrm{~m}^{2}$ ) or severe renal impairment (eGFR less than $30 \mathrm{~mL} / \mathrm{min} / 1.73 \mathrm{~m}^{2}$ ) and in HD subjects, and compared with subjects with normal renal function. The sofosbuvir AUC was $107 \%$ and $171 \%$ higher in the patients with moderate and severe renal impairment, compared with the control subjects. The GS-331007 AUC was $88 \%$ and $451 \%$ higher in the patients with moderate and severe renal impairment, respectively. In the dialysis subjects, the sofosbuvir AUC was $28-60 \%$ higher, compared to the control subjects, when sofosbuvir was administered before or after HD. The GS-331007 AUC in the dialysis subjects was $1280 \%$ or $2070 \%$ higher than in the control subjects when sofosbuvir was administered before or after HD. ${ }^{73}$ Thus, exposure of sofosbuvir and of the metabolite GS-331007 are considered to be quite increased in patients with renal dysfunction. Quite recently, Desnoyer et al. ${ }^{74}$ reported the pharmacokinetics and safety of a sofosbuvir-containing regime in dialysis patients. They showed that sofosbuvir plasma concentrations were never detectable before and after the HD and, on the contrary to previously reported results in patients with normal renal function, higher GS-331007 plasma concentrations were observed. However, no GS-331007 accumulation was observed, and the regimen was well tolerated generally. Nevertheless, until now sofosbuvir has not been recommended for patients with renal dysfunction, and in some countries it is even contraindicated. ${ }^{75}$ Further large-number studies are necessary. 
Several studies about sofosbuvir-based therapy for patients with renal dysfunction have been recently reported. ${ }^{76-79}$ Saxena et al. $^{79}$ reported the outcomes of sofosbuvir-based therapy for patients with renal dysfunction by using the HCVTARGET database, which is a multicenter, real-world cohort. Of the 1789 enrolled patients, 73 had eGFR of less than $45 \mathrm{~mL} /$ $\mathrm{min} / 1.73 \mathrm{~m}^{2}$ (18 patients with eGFR $\leq 30 \mathrm{~mL} / \mathrm{min} / 1.73 \mathrm{~m}^{2}$ and 5 patients on dialysis). These patients were compared to 1716 patients with eGFR $>45 \mathrm{~mL} / \mathrm{min} / 1.73 \mathrm{~m}^{2}$. The included treatment regimen was sofosbuvir/simeprevir at $40 \%$, sofosbuvir/RBV at 30\%, sofosbuvir/PEG-INF/RBV at $18 \%$ and sofosbuvir/simeprevir/RBV at $11 \%$; all patients with eGFR $\leq 45 \mathrm{~mL} / \mathrm{min} / 1.73 \mathrm{~m}^{2}$ were treated with sofosbuvir $400 \mathrm{mg}$ once a day. Patients with baseline eGFR $\leq 45 \mathrm{~mL} / \mathrm{min} /$ $1.73 \mathrm{~m}^{2}$ had a significantly higher rate of cirrhosis $(73 \%)$ as compared with the control group (24\%). SVR 12 was achieved in 53 of the $64(83 \%)$ patients with eGFR $<45 \mathrm{~mL} / \mathrm{min} / 1.73 \mathrm{~m}^{2}$; this was comparable to patients with eGFR $>45 \mathrm{~mL} / \mathrm{min} /$ $1.73 \mathrm{~m}^{2}$. In addition, 15 of the $17(88 \%)$ patients with eGFR $\leq 30 \mathrm{~mL} / \mathrm{min} / 1.73 \mathrm{~m}^{2}$ and all 5 patients on HD at baseline achieved $\mathrm{SVR}_{12}$. However, in the safety analysis, the patients with eGFR $\leq 45 \mathrm{~mL} / \mathrm{min} / 1.73 \mathrm{~m}^{2}$ were found to have experienced significantly higher rates of anemia (31\%), worsening of the renal function (10\%), and any serious AEs (18\%). The authors concluded that patients with renal impairment need close expert monitoring.

On the other hand, Nazario et al. ${ }^{80}$ reported that 15 dialysis patients and 2 patients with severe renal dysfunction all achieved $S R_{12}$, with only mild AEs experienced by patients on the sofosbuvir and simeprevir combination therapy. Singh et al. ${ }^{83}$ reported that 8 dialysis patients received sofosbuvirbased therapy (4 patients with ledipasvir and 4 patients with simeprevir) and $7(88 \%)$ achieved $\mathrm{SVR}_{12}$. In addition, some studies on sofosbuvir plus RBV or ledipasvir/sofosbuvir in adults with HCV infection and renal insufficiency are still ongoing (NCT01958281). Thus, the results of the clinical trials are expected.

\section{Conclusion}

In this review, we described the efficacy, safety and pharmacokinetics of novel anti-HCV drugs in patients with severe renal dysfunction. These data reveal that grazoprevir/elbasvir combination therapy, PTV/ritonavir/OBV with or without DSV therapy, and DCV/ASV combination therapy are highly effective and safe for patients with severe renal dysfunction. Sofosbuvir is highly effective and has high genetic barrier, thus representing one of the key drugs for anti-HCV therapy; however, data on sofosbuvir treatment for patients with severe renal dysfunction are still pending. The results of ongoing clinical trials are expected. Therefore, the use of sofosbuvir to treat HCV-infected patients with eGFR $<30 \mathrm{~mL}$ / $\mathrm{min} / 1.73 \mathrm{~m}^{2}$ or on-dialysis remains off-label and should be left to experienced physicians or centers, and administered with full consent of the treated patients.

Timing of HCV treatment in a kidney transplant candidate might depend on the waiting time for the kidney transplant. If the waiting time is lengthy, prompt DAAs therapy is necessary, because of several treatment benefits, including restored liver function. ${ }^{42}$ On the other hand, if the waiting time is short, because favorable outcomes of either pre- or post-kidney transplant DAAs treatment have been reported, ${ }^{40-42,72,81}$ both timing could be selected.
According to the emerging data, the standard therapy for HCV-infected patients with severe renal dysfunction will likely change from IFN-based therapy to IFN-free DAAs-based therapy. However, the data to date have been mainly limited to genotype 1-infected patients with severe renal dysfunction. Therefore, if a good prognosis is expected, dialysis patients with genotype $1 \mathrm{HCV}$ infection should be considered for DAAs therapy. In dialysis patients with HCV infection other than genotype 1 , except for dialysis patients for whom prompt treatment would be required, waiting for the next-generation DAAs would be the optimal treatment option; this is because clinical trials on the next-generation pan-genotypic DAAs therapy, which are expected to be possible to administer in patients with renal dysfunction, are underway. ${ }^{82}$ In addition, real world data are still limited. Further investigations are still necessary.

\section{Acknowledgements}

This study was supported in part by grants from the Ministry of Education, Culture, Sports, Science and Technology of Japan and the Japan Agency for Medical Research and Development.

\section{Conflict of interest}

Professor Naoya Sakamoto received lecture fees from Bristol Myers Squibb and Pharmaceutical K.K, grants and endowments from MSD K.K and Chugai Pharmaceutical Co., Ltd, and a research grant from Gilead Sciences, Inc. Dr. Goki Suda received research grants from Bristol Myers Squibb. The other authors have nothing to disclose.

\section{Author contributions}

Conceived the topic of the review article (GS), collected and reviewed articles (GS, KO, MK, KM, NS), wrote the manuscript and reviewed the final version (GS, KO, MK, KM, NS), collected the data and created the figure and table (GS, MK, MN, TS).

\section{References}

[1] Gower E, Estes C, Blach S, Razavi-Shearer K, Razavi H. Global epidemiology and genotype distribution of the hepatitis $C$ virus infection. J Hepatol 2014; 61:S45-S57. doi: 10.1016/j.jhep.2014.07.027.

[2] Mohd Hanafiah K, Groeger J, Flaxman AD, Wiersma ST. Global epidemiology of hepatitis $C$ virus infection: new estimates of age-specific antibody to HCV seroprevalence. Hepatology 2013;57:1333-1342. doi: 10.1002/hep.26141.

[3] Seeff LB. Natural history of chronic hepatitis C. Hepatology 2002;36:S35S46. doi: $10.1053 /$ jhep.2002.36806.

[4] Iwasa Y, Otsubo S, Sugi O, Sato K, Asamiya Y, Eguchi A, et al. Patterns in the prevalence of hepatitis $C$ virus infection at the start of hemodialysis in Japan. Clin Exp Nephrol 2008;12:53-57. doi: 10.1007/s10157-007-0005-6.

[5] Bergman S, Accortt N, Turner A, Glaze J. Hepatitis C infection is acquired preESRD. Am J Kidney Dis 2005;45:684-689.

[6] Di Napoli A, Pezzotti P, Di Lallo D, Petrosillo N, Trivelloni C, Di Giulio S, et al. Epidemiology of hepatitis $C$ virus among long-term dialysis patients: a 9-year study in an Italian region. Am J Kidney Dis 2006;48:629-637. doi: 10. 1053/j.ajkd.2006.07.004

[7] Fissell RB, Bragg-Gresham JL, Woods JD, Jadoul M, Gillespie B, Hedderwick $\mathrm{SA}$, et al. Patterns of hepatitis $C$ prevalence and seroconversion in hemodialysis units from three continents: the DOPPS. Kidney Int 2004;65:23352342. doi: 10.1111/j.1523-1755.2004.00649.x.

[8] Sun J, Yu R, Zhu B, Wu J, Larsen S, Zhao W. Hepatitis C infection and related factors in hemodialysis patients in china: systematic review and metaanalysis. Ren Fail 2009;31:610-620. 10.1080/08860220903003446. 
[9] Alavian SM, Kabir A, Ahmadi AB, Lankarani KB, Shahbabaie MA, AhmadzadAsl M. Hepatitis $C$ infection in hemodialysis patients in Iran: a systematic review. Hemodial Int 2010;14:253-262. doi: 10.1111/j.1542-4758.2010. 00437.x.

[10] Gill K, Ghazinian H, Manch R, Gish R. Hepatitis C virus as a systemic disease: reaching beyond the liver. Hepatol Int 2016;10:415-423. doi: 10.1007/ s12072-015-9684-3.

[11] Fabrizi F, Plaisier E, Saadoun D, Martin P, Messa P, Cacoub P. Hepatitis C virus infection, mixed cryoglobulinemia, and kidney disease. Am J Kidney Dis 2013;61:623-637. doi: 10.1053/j.ajkd.2012.08.040.

[12] Lee JJ, Lin MY, Chang JS, Hung CC, Chang JM, Chen HC, et al. Hepatitis C virus infection increases risk of developing end-stage renal disease using competing risk analysis. PLoS One 2014;9:e100790. doi: 10.1371/journal. pone.0100790.

[13] Misiani R, Bellavita P, Fenili D, Vicari O, Marchesi D, Sironi PL, et al. Interferon alfa-2a therapy in cryoglobulinemia associated with hepatitis $C$ virus. $\mathrm{N}$ Engl J Med 1994;330:751-756. doi: 10.1056/NEJM199403173301104.

[14] Tsuge M, Hiramatsu A, Shinohara F, Nakano N, Nakamura Y, Hatooka M, et al. Improvement of renal dysfunction in a patient with hepatitis $C$ virus-related liver cirrhosis by daclatasvir and asunaprevir combination therapy: A case report. Hepatol Res 2016;46:944-948. doi: 10.1111/hepr.12629.

[15] Hsu YC, Ho HJ, Huang YT, Wang HH, Wu MS, Lin JT, et al. Association between antiviral treatment and extrahepatic outcomes in patients with hepatitis $C$ virus infection. Gut 2015;64:495-503. doi: 10.1136/gutjnl-2014-308163.

[16] Kalantar-Zadeh K, Kilpatrick RD, McAllister CJ, Miller LG, Daar ES, Gjertson DW, et al. Hepatitis $C$ virus and death risk in hemodialysis patients. J Am Soc Nephrol 2007;18:1584-1593. doi: 10.1681/ASN.2006070736.

[17] Nakayama E, Akiba T, Marumo F, Sato C. Prognosis of anti-hepatitis C virus antibody-positive patients on regular hemodialysis therapy. J Am Soc Nephrol 2000;11:1896-1902.

[18] Goodkin DA, Bragg-Gresham JL, Koenig KG, Wolfe RA, Akiba T, Andreucci VE, et al. Association of comorbid conditions and mortality in hemodialysis patients in Europe, Japan, and the United States: the Dialysis Outcomes and Practice Patterns Study (DOPPS). J Am Soc Nephrol 2003;14:32703277.

[19] Fabrizi F, Takkouche B, Lunghi G, Dixit V, Messa P, Martin P. The impact of hepatitis $C$ virus infection on survival in dialysis patients: meta-analysis of observational studies. J Viral Hepat 2007;14:697-703. doi: 10.1111/j. 1365-2893.2007.00868.x

[20] Mathurin P, Mouquet C, Poynard T, Sylla C, Benalia H, Fretz C, et al. Impact of hepatitis $B$ and $C$ virus on kidney transplantation outcome. Hepatology 1999; 29:257-263. doi: 10.1002/hep.510290123.

[21] Akiba T, Hora K, Imawari M, Sato C, Tanaka E, Izumi N, et al. 2011 Japanese Society for Dialysis Therapy guidelines for the treatment of hepatitis $C$ virus infection in dialysis patients. Ther Apher Dial 2012;16:289-310. doi: 10 . 1111/j.1744-9987.2012.01078.x.

[22] Kidney Disease: Improving Global Outcomes (KDIGO). KDIGO clinical practice guidelines for the prevention, diagnosis, evaluation, and treatment of hepatitis C in chronic kidney disease. Kidney Int Suppl 2008:S1-S99. doi: 10.1038/ki.2008.81.

[23] Davis GL, Albright JE, Cook SF, Rosenberg DM. Projecting future complications of chronic hepatitis $C$ in the United States. Liver Transpl 2003;9: 331-338. doi: $10.1053 /$ jlts.2003.50073.

[24] Taura N, Hamasaki K, Nakao K, Ichikawa T, Nishimura D, Goto T, et al. Aging of patients with hepatitis $C$ virus-associated hepatocellular carcinoma: longterm trends in Japan. Oncol Rep 2006;16:837-843.

[25] Walker WG, Neaton JD, Cutler JA, Neuwirth R, Cohen JD. Renal function change in hypertensive members of the Multiple Risk Factor Intervention Trial. Racial and treatment effects. The MRFIT Research Group. JAMA 1992; 268:3085-3091.

[26] Fabrizi F, Dixit V, Messa P, Martin P. Interferon monotherapy of chronic hepatitis $C$ in dialysis patients: meta-analysis of clinical trials. J Viral Hepat 2008;15:79-88. doi: 10.1111/j.1365-2893.2007.00907.x.

[27] Gordon CE, Uhlig K, Lau J, Schmid CH, Levey AS, Wong JB. Interferon treatment in hemodialysis patients with chronic hepatitis $C$ virus infection: a systematic review of the literature and meta-analysis of treatment efficacy and harms. Am J Kidney Dis 2008;51:263-277. doi: 10.1053/j.ajkd.2007. 11.003.

[28] Ayaz C, Celen MK, Yuce UN, Geyik MF. Efficacy and safety of pegylatedinterferon alpha-2a in hemodialysis patients with chronic hepatitis $\mathrm{C}$. World J Gastroenterol 2008;14:255-259.

[29] Tanaka Y, Nishida N, Sugiyama M, Kurosaki M, Matsuura K, Sakamoto N, et al. Genome-wide association of IL28B with response to pegylated interferon-alpha and ribavirin therapy for chronic hepatitis C. Nat Genet 2009;41:1105-1109. doi: 10.1038/ng.449.

[30] Tsunematsu S, Suda G, Yamasaki K, Kimura M, Izumi T, Umemura M, et al. Hepatitis $B$ virus $X$ protein impairs $\alpha$-interferon signaling via up-regulation of suppressor of cytokine signaling 3 and protein phosphatase 2A. J Med Virol 2017;89:267-275. doi: 10.1002/jmv.24643.
[31] Suda G, Sakamoto N, Itsui Y, Nakagawa M, Tasaka-Fujita M, Funaoka Y, et al. IL-6-mediated intersubgenotypic variation of interferon sensitivity in hepatitis $C$ virus genotype $2 a / 2 b$ chimeric clones. Virology 2010;407:8090. doi: 10.1016/j.virol.2010.07.041.

[32] Lohmann V, Körner F, Koch J, Herian U, Theilmann L, Bartenschlager R. Replication of subgenomic hepatitis $C$ virus RNAs in a hepatoma cell line. Science 1999;285:110-113.

[33] Mizokami M, Yokosuka O, Takehara T, Sakamoto $\mathrm{N}$, Korenaga M, Mochizuki $\mathrm{H}_{\text {, }}$ et al. Ledipasvir and sofosbuvir fixed-dose combination with and without ribavirin for 12 weeks in treatment-naive and previously treated Japanese patients with genotype 1 hepatitis C: an open-label, randomised, phase 3 trial. Lancet Infect Dis 2015;15:645-653. doi: 10.1016/S1473-3099(15) 70099-X.

[34] Omata M, Nishiguchi S, Ueno Y, Mochizuki H, Izumi N, Ikeda F, et al. Sofosbuvir plus ribavirin in Japanese patients with chronic genotype $2 \mathrm{HCV}$ infection: an open-label, phase 3 trial. J Viral Hepat 2014;21:762-768. doi: 10. $1111 /$ jvh.12312.

[35] Kumada H, Hayashi N, Izumi N, Okanoue T, Tsubouchi H, Yatsuhashi H, et al. Simeprevir (TMC435) once daily with peginterferon- $\alpha-2 b$ and ribavirin in patients with genotype 1 hepatitis $\mathrm{C}$ virus infection: The CONCERTO-4 study. Hepatol Res 2015;45:501-513. doi: 10.1111/hepr.12375.

[36] Poordad F, Hezode C, Trinh R, Kowdley KV, Zeuzem S, Agarwal K, et al. ABT450/r-ombitasvir and dasabuvir with ribavirin for hepatitis $C$ with cirrhosis. N Engl J Med 2014;370:1973-1982. doi: 10.1056/NEJMoa1402869.

[37] Bristol-Myers Squibb Company. Sunvepra capsules (asunaprevir) Japanese Prescribing Information. 2014.

[38] Ito J, Suda G, Yamamoto Y, Nagasaka A, Furuya K, Kumagai K, et al. Prevalence and characteristics of naturally occurring sofosbuvir resistanceassociated variants in patients with hepatitis $C$ virus genotype $1 \mathrm{~b}$ infection. Hepatol Res 2016;46:1294-1303. doi: 10.1111/hepr.12685.

[39] Kumada H, Suzuki Y, Ikeda K, Toyota J, Karino Y, Chayama K, et al. Daclatasvir plus asunaprevir for chronic HCV genotype $1 \mathrm{~b}$ infection. Hepatology 2014;59:2083-2091. doi: 10.1002/hep.27113.

[40] Roth D, Nelson DR, Bruchfeld A, Liapakis A, Silva M, Monsour H Jr, et al. Grazoprevir plus elbasvir in treatment-naive and treatment-experienced patients with hepatitis $C$ virus genotype 1 infection and stage 4-5 chronic kidney disease (the C-SURFER study): a combination phase 3 study. Lancet 2015;386:1537-1545. doi: 10.1016/S0140-6736(15)00349-9.

[41] Pockros PJ, Reddy KR, Mantry PS, Cohen E, Bennett M, Sulkowski MS, et al. Efficacy of direct-acting antiviral combination for patients with hepatitis $C$ virus genotype 1 infection and severe renal impairment or end-stage renal disease. Gastroenterology 2016;150:1590-1598. doi: 10.1053/j.gastro. 2016.02.078.

[42] Suda G, Kudo M, Nagasaka A, Furuya K, Yamamoto Y, Kobayashi T, et al. Efficacy and safety of daclatasvir and asunaprevir combination therapy in chronic hemodialysis patients with chronic hepatitis C. J Gastroenterol 2016;51:733-740. doi: 10.1007/s00535-016-1162-8.

[43] REBETOL ${ }^{\circledR}$ (ribavirin USP) capsules, for oral use. Merck \& Co., Inc. Available from: https://www.merck.com/product/usa/pi_circulars/r/rebetol/rebetol_ pi.pdf, 2016.

[44] Fabrizi F, Dixit V, Messa P, Martin P. Pegylated interferon mono-therapy of chronic hepatitis $C$ in the dialysis population: systematic review and meta-analysis. Ther Apher Dial 2015;19:611-621. doi: 10.1111/17449987.12318.

[45] Fabrizi F, Dixit V, Messa P, Martin P. Antiviral therapy (pegylated interferon and ribavirin) of hepatitis $C$ in dialysis patients: meta-analysis of clinical studies. J Viral Hepat 2014;21:681-689. doi: 10.1111/jvh.12276.

[46] Kumada H, Toyota J, Okanoue T, Chayama K, Tsubouchi H, Hayashi N. Telaprevir with peginterferon and ribavirin for treatment-naive patients chronically infected with HCV of genotype 1 in Japan. J Hepatol 2012;56:78-84. doi: 10.1016/j.jhep.2011.07.016.

[47] Poordad F, McCone J Jr, Bacon BR, Bruno S, Manns MP, Sulkowski MS, et al. Boceprevir for untreated chronic HCV genotype 1 infection. N Engl J Med 2011;364:1195-1206. doi: 10.1056/NEJMoa1010494.

[48] Bacon BR, Gordon SC, Lawitz E, Marcellin P, Vierling JM, Zeuzem S, et al. Boceprevir for previously treated chronic HCV genotype 1 infection. N Engl J Med 2011;364:1207-1217. doi: 10.1056/NEJMoa1009482.

[49] Suda G, Yamamoto Y, Nagasaka A, Furuya K, Kudo M, Chuganji Y, et al. Serum granulysin levels as a predictor of serious telaprevir-induced dermatological reactions. Hepatol Res 2015;45:837-845. doi: 10.1111/hepr. 12421.

[50] Karino T, Ozeki I, Hige S, Kimura M, Arakawa T, Nakajima T, et al. Telaprevir impairs renal function and increases blood ribavirin concentration during telaprevir/pegylated interferon/ribavirin therapy for chronic hepatitis C. J Viral Hepat 2014;21:341-347. doi: 10.1111/jvh.12162.

[51] Dumortier J, Guillaud O, Gagnieu MC, Janbon B, Juillard L, Morelon E, et al. Anti-viral triple therapy with telaprevir in haemodialysed HCV patients: is it feasible? J Clin Virol 2013;56:146-149. doi: 10.1016/j.jcv.2012.10.009.

[52] Wiegand J, Maasoumy B, Buggisch P, Buslau A, Schiefke I, Berg T, et al. Letter: Telaprevir triple therapy in chronic hepatitis $C$ genotype 1 patients 
receiving haemodialysis. Aliment Pharmacol Ther 2014;39:1342-1344. doi: 10.1111/apt.12748.

[53] Knapstein J, Galle PR, Zimmermann T. Antiviral triple therapy with boceprevir in a chronic hepatitis $C$ haemodialysis patient awaiting kidney re-transplantation. Dig Liver Dis 2014;46:88-89. doi: 10.1016/j.dld.2013. 08.133.

[54] de Kanter CT, den Hollander JG, Verweij-van Wissen CP, Burger DM. Telaprevir pharmacokinetics in a hepatitis $C$ virus infected patient on haemodialysis. J Clin Virol 2014;60:431-432. doi: 10.1016/j.jcv.2014.05.008.

[55] Mehawej M, Rostaing L, Alric L, Del Bello A, Izopet J, Kamar N. Boceprevirbased triple antiviral therapy for chronic hepatitis $C$ virus infection in kidneytransplant candidates. J Transplant 2015;2015:159795. doi: 10.1155/2015/ 159795.

[56] Summa V, Ludmerer SW, McCauley JA, Fandozzi C, Burlein C, Claudio G, et al. MK-5172, a selective inhibitor of hepatitis C virus NS3/4a protease with broad activity across genotypes and resistant variants. Antimicrob Agents Chemother 2012;56:4161-4167. doi: 10.1128/AAC.00324-12.

[57] ZEPATIER ${ }^{\mathrm{TM}}$ (elbasvir and grazoprevir) tablets, for oral use. Merck \& Co., Inc. Available from: https://www.merck.com/product/usa/pi_circulars/z/zepatier/zepatier_pi.pdf, 2016.

[58] Liu R, Curry S, McMonagle P, Yeh WW, Ludmerer SW, Jumes PA, et al. Susceptibilities of genotype $1 \mathrm{a}, 1 \mathrm{~b}$, and 3 hepatitis $C$ virus variants to the NS5A inhibitor elbasvir. Antimicrob Agents Chemother 2015;59:6922-6929. doi: 10.1128/AAC.01390-15.

[59] Forns X, Gordon SC, Zuckerman E, Lawitz E, Calleja JL, Hofer H, et al. Grazoprevir and elbasvir plus ribavirin for chronic HCV genotype-1 infection after failure of combination therapy containing a direct-acting antiviral agent. J Hepatol 2015;63:564-572. doi: 10.1016/j.jhep.2015.04.009.

[60] Lawitz E, Gane E, Pearlman B, Tam E, Ghesquiere W, Guyader D, et al. Efficacy and safety of 12 weeks versus 18 weeks of treatment with grazoprevir (MK-5172) and elbasvir (MK-8742) with or without ribavirin for hepatitis C virus genotype 1 infection in previously untreated patients with cirrhosis and patients with previous null response with or without cirrhosis (C-WORTHY): a randomised, open-label phase 2 trial. Lancet 2015;385:1075-1086. doi: 10. 1016/S0140-6736(14)61795-5.

[61] Sulkowski M, Hezode C, Gerstoft J, Vierling JM, Mallolas J, Pol S, et al. Efficacy and safety of 8 weeks versus 12 weeks of treatment with grazoprevir (MK-5172) and elbasvir (MK-8742) with or without ribavirin in patients with hepatitis $C$ virus genotype 1 mono-infection and HIV/hepatitis $C$ virus coinfection (C-WORTHY): a randomised, open-label phase 2 trial. Lancet 2015; 385:1087-1097. doi: 10.1016/S0140-6736(14)61793-1.

[62] Buti M, Gordon SC, Zuckerman E, Lawitz E, Calleja JL, Hofer H, et al. Grazoprevir, elbasvir, and ribavirin for chronic hepatitis $C$ virus genotype 1 infection after failure of pegylated interferon and ribavirin with an earlier-generation protease inhibitor: final 24-week results from C-SALVAGE. Clin Infect Dis 2016;62:32-36. doi: 10.1093/cid/civ722.

[63] Rockstroh JK, Nelson M, Katlama C, Lalezari J, Mallolas J, Bloch M, et al. Efficacy and safety of grazoprevir (MK-5172) and elbasvir (MK-8742) in patients with hepatitis $C$ virus and HIV co-infection (C-EDGE CO-INFECTION): a non-randomised, open-label trial. Lancet HIV 2015;2:e319-e327. doi: 10. 1016/S2352-3018(15)00114-9.

[64] VIEKIRA PAK (ombitasvir, paritaprevir, and ritonavir tablets; dasabuvir tablets), co-packaged for oral use. AbbVie Inc., available from: https: //www.accessdata.fda.gov/drugsatfda_docs/label/2014/206619lbl.pdf, 2016.

[65] Ferenci P, Bernstein D, Lalezari J, Cohen D, Luo Y, Cooper C, et al. ABT-450/rombitasvir and dasabuvir with or without ribavirin for HCV. N Engl J Med 2014;370:1983-1992. doi: 10.1056/NEJMoa1402338.

[66] Zeuzem S, Jacobson IM, Baykal T, Marinho RT, Poordad F, Bourlière M, et al. Retreatment of HCV with ABT-450/r-ombitasvir and dasabuvir with ribavirin. N Engl J Med 2014;370:1604-1614. doi: 10.1056/NEJMoa1401561.

[67] Gao M. Antiviral activity and resistance of HCV NS5A replication complex inhibitors. Curr Opin Virol 2013;3:514-520. doi: 10.1016/j.coviro.2013. 06.014 .
[68] Kawakami $Y$, Imamura $M$, Ikeda $H$, Suzuki $M$, Arataki $K$, Moriishi $M$, et al. Pharmacokinetics, efficacy and safety of daclatasvir plus asunaprevir in dialysis patients with chronic hepatitis C: pilot study. J Viral Hepat 2016; 23:850-856. doi: $10.1111 /$ jvh. 12553 .

[69] Daklinza (daclatasvir) tablets prescibing information. Tokyo, Japan: BristolMyers KK; 2014.

[70] Kumada H, Suzuki F, Suzuki Y, Toyota J, Karino Y, Chayama K, et al. Randomized comparison of daclatasvir + asunaprevir versus telaprevir + peginterferon/ribavirin in Japanese hepatitis C virus patients. J Gastroenterol Hepatol 2016;31:14-22. doi: 10.1111/jgh.13073.

[71] Manns M, Pol S, Jacobson IM, Marcellin P, Gordon SC, Peng CY, et al. All-oral daclatasvir plus asunaprevir for hepatitis $C$ virus genotype $1 \mathrm{~b}$ : a multinational, phase 3, multicohort study. Lancet 2014;384:1597-1605. doi: 10. 1016/S0140-6736(14)61059-X.

[72] Toyoda H, Kumada T, Tada T, Takaguchi K, Ishikawa T, Tsuji K, et al. Safety and efficacy of dual direct-acting antiviral therapy (daclatasvir and asunaprevir) for chronic hepatitis $C$ virus genotype 1 infection in patients on hemodialysis. J Gastroenterol 2016;51:741-747. doi: 10.1007/s00535016-1174-4.

[73] SOVALDI ${ }^{\circledR}$ (sofosbuvir) tablets, for oral use. Gilead Sciences, Inc., available from: http://www.gilead.com/ /media/Files/pdfs/medicines/liver-disease/ sovaldi/sovaldi_pi.pdf, 2015.

[74] Desnoyer A, Pospai D, Lê MP, Gervais A, Heurgué-Berlot A, Laradi A, et al. Pharmacokinetics, safety and efficacy of a full dose sofosbuvir-based regimen given daily in hemodialysis patients with chronic hepatitis $\mathrm{C}$. J Hepatol 2016;65:40-47. doi: 10.1016/j.jhep.2016.02.044.

[75] Asahina Y, Izumi N, Hiromitsu K, Kurosaki M, Koike K, Suzuki F, et al. JSH Guidelines for the Management of Hepatitis C Virus Infection: A 2016 update for genotype 1 and 2. Hepatol Res 2016;46:129-165. doi: 10.1111/hepr. 12645.

[76] Hundemer GL, Sise ME, Wisocky J, Ufere N, Friedman LS, Corey KE, et al. Use of sofosbuvir-based direct-acting antiviral therapy for hepatitis $C$ viral infection in patients with severe renal insufficiency. Infect Dis (Lond) 2015;47: 924-929. doi: 10.3109/23744235.2015.1078908.

[77] Perumpail RB, Wong RJ, Ha LD, Pham EA, Wang U, Luong H, et al. Sofosbuvir and simeprevir combination therapy in the setting of liver transplantation and hemodialysis. Transpl Infect Dis 2015;17:275-278. doi: 10.1111/tid. 12348.

[78] Perumpail RB, Wong RJ, Pham EA, Higgins JP, Daugherty TJ, Ahmed A. A new standard of care? standard dose sofosbuvir in an HCV-infected liver transplant recipient undergoing hemodialysis. Dig Dis Sci 2016;61:39-41. doi: 10.1007/s10620-015-3756-z

[79] Saxena V, Koraishy FM, Sise ME, Lim JK, Schmidt M, Chung RT, et al. Safety and efficacy of sofosbuvir-containing regimens in hepatitis C-infected patients with impaired renal function. Liver Int 2016;36:807-816. doi: 10 . 1111/liv.13102.

[80] Nazario HE, Ndungu M, Modi AA. Sofosbuvir and simeprevir in hepatitis $C$ genotype 1-patients with end-stage renal disease on haemodialysis or GFR $<30 \mathrm{ml} / \mathrm{min}$. Liver Int 2016;36:798-801. doi: 10.1111/liv.13025.

[81] Scalea JR, Barth RN, Munivenkatappa R, Philosophe B, Cooper M, Whitlow V, et al. Shorter waitlist times and improved graft survivals are observed in patients who accept hepatitis $\mathrm{C}$ virus+ renal allografts. Transplantation 2015;99:1192-1196. doi: 10.1097/TP.0000000000000479.

[82] Asselah T, Boyer N, Saadoun D, Martinot-Peignoux M, Marcellin P. Directacting antivirals for the treatment of hepatitis $C$ virus infection: optimizing current IFN-free treatment and future perspectives. Liver Int 2016;36 Suppl 1:47-57. doi: 10.1111/liv.13027.

[83] Singh T, Guirguis J, Anthony S, Rivas J, Hanouneh IA, Alkhouri N. Sofosbuvirbased treatment is safe and effective in patients with chronic hepatitis $C$ infection and end stage renal disease: a case series. Liver Int 2016;36: 802-806. doi: 10.1111/liv.13078.

[84] Beinhardt S, Al Zoairy R, Ferenci P, Kozbial K, Freissmuth C, Stern R, et al. DAA-based antiviral treatment of patients with chronic hepatitis $C$ in the preand postkidney transplantation setting. Transpl Int 2016;29:999-1007. doi: 10.1111/tri.12799. 